Mesa Redonda: A comunicação científica no Brasil: estratégias de diálogo científico em âmbito internacional

\title{
Na estrada de Wells a Wales: O que esperar nos próximos passos do Portal da UFSC
}

Roberto Pacheco

Programa de Pós-Graduação em Engenharia

e Gestão do Conhecimento - UFSC - pacheco@egc.ufsc.br 


\section{Como se (re)produz um dos}

principais produtos da ciência?

Como surgem os artigos? 



\section{Em 1937...}

Durante o século XIX as enciclopédias seguiram o padrão e a escala do século XVIII, apesar do crescimento gigantesco de conhecimento registrado e do crescimento ainda maior do número de pessoas necessitando acesso facilitado à informação.

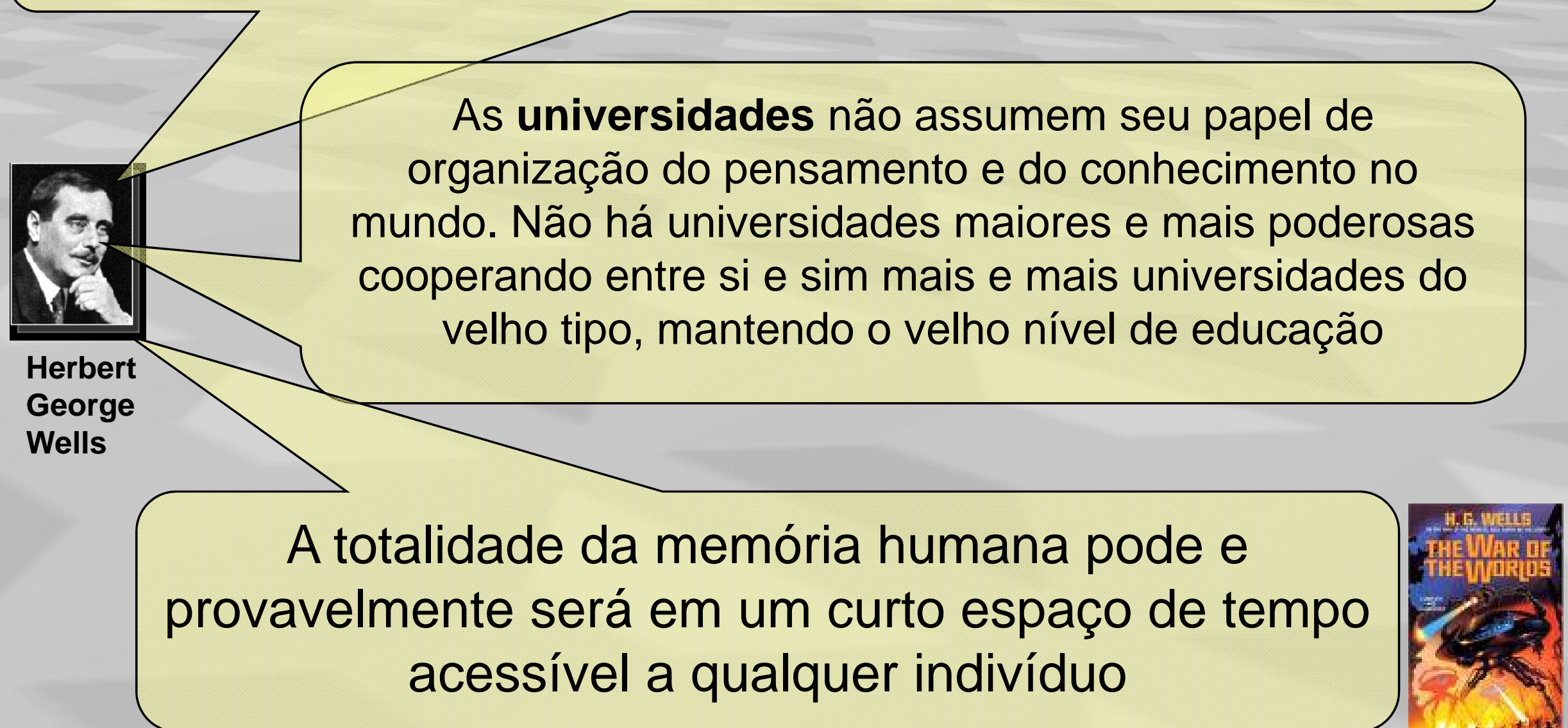




\section{4 anos depois...(em 1991)}

The problem with the global village is all the global village idiots.

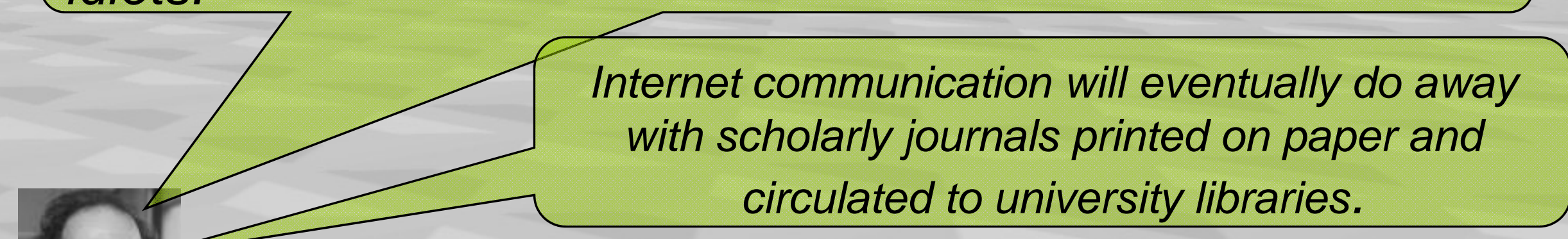

"We're trying to evolve one model component of what we hope will become some overall seamless infrastructure for scholarly research communication and continue to remain

Paul

Ginsparg

\section{in step with rapid technological changes."}

Los Alamos National Laboratory (90-01)

170.000 submissões de artigos em 10 anos

50175 conexões hoje às $10 \mathrm{hs}$

Cornell University Library

arXiv.org 


\section{A partir de $1998 . .$.}

Imagine o mundo onde cada pessoa do planeta tem acesso livre à soma de todo o conhecimento humano. É isso que estamos fazendo.

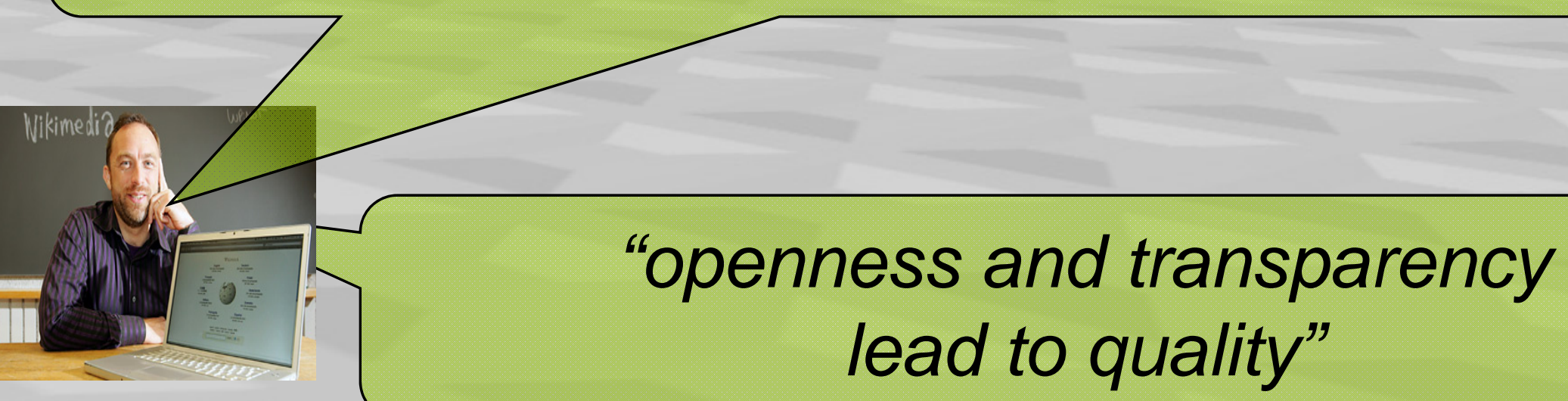

Jimmy

Wales

WIKIPEDIA

684 million visitors annually

10 million articles in 253 languages

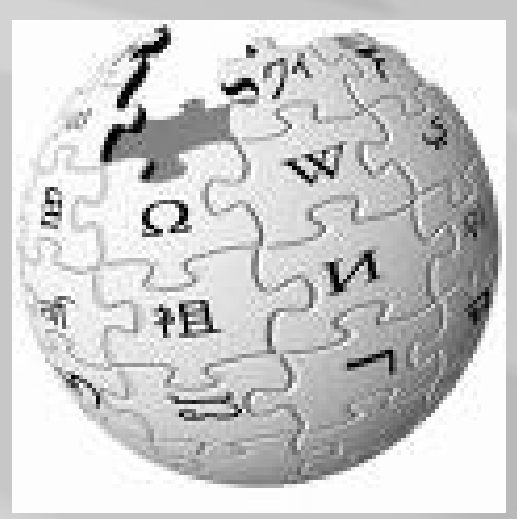




\section{Como se (re)produz o principal produto da ciência?}

Repensando... 


\section{Novas possibilidades da sociedade do conhecimento}

\begin{tabular}{|l|}
\hline Investigação \\
\hline VirtualLabs \\
Virtual \\
Research \\
Groups \\
Research \\
Networks \\
CoP
\end{tabular}

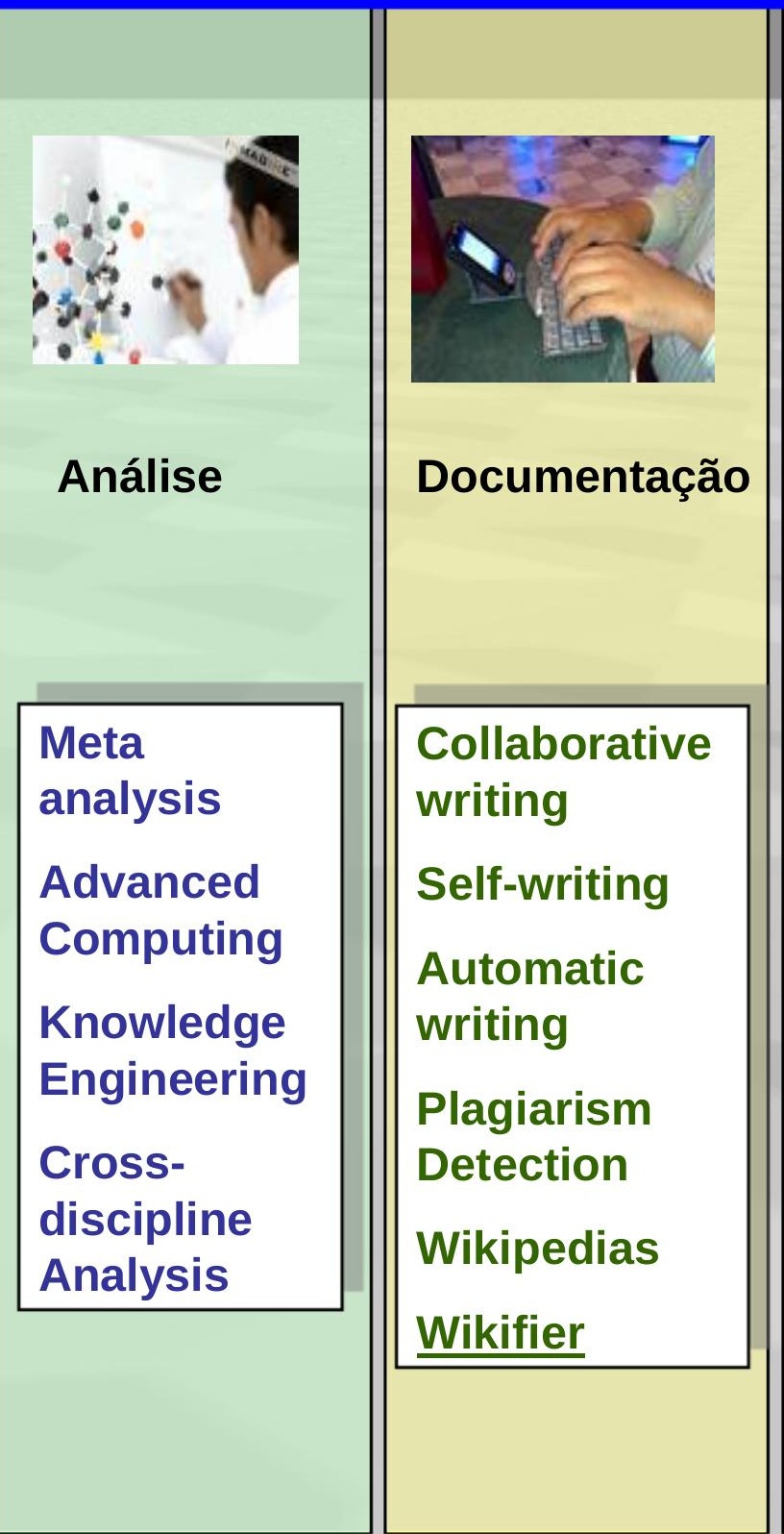
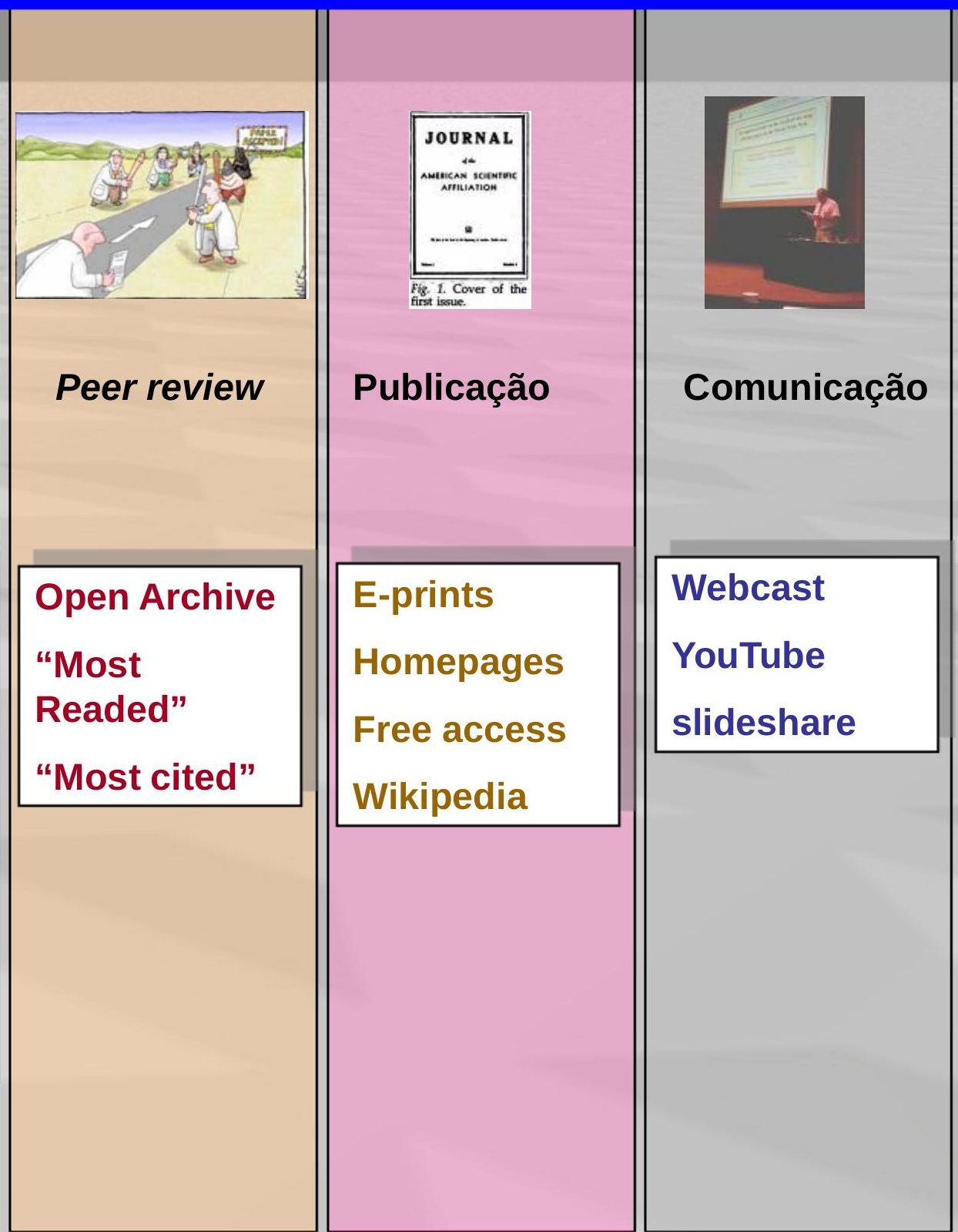


\section{O Portal da ijecis}

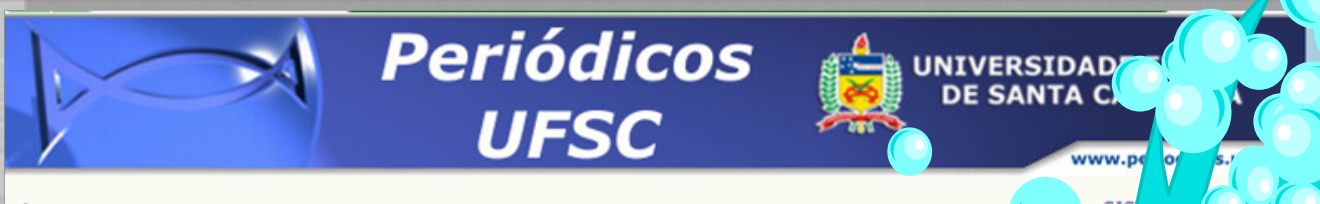

PÁgINA INICIAL SOBRE ACESSO CADASTRO PESQUisa

Página inicial > Sistema Eletrônico de Editoração de Revistas

Sistema Eletrônico de Editoração de Revistas

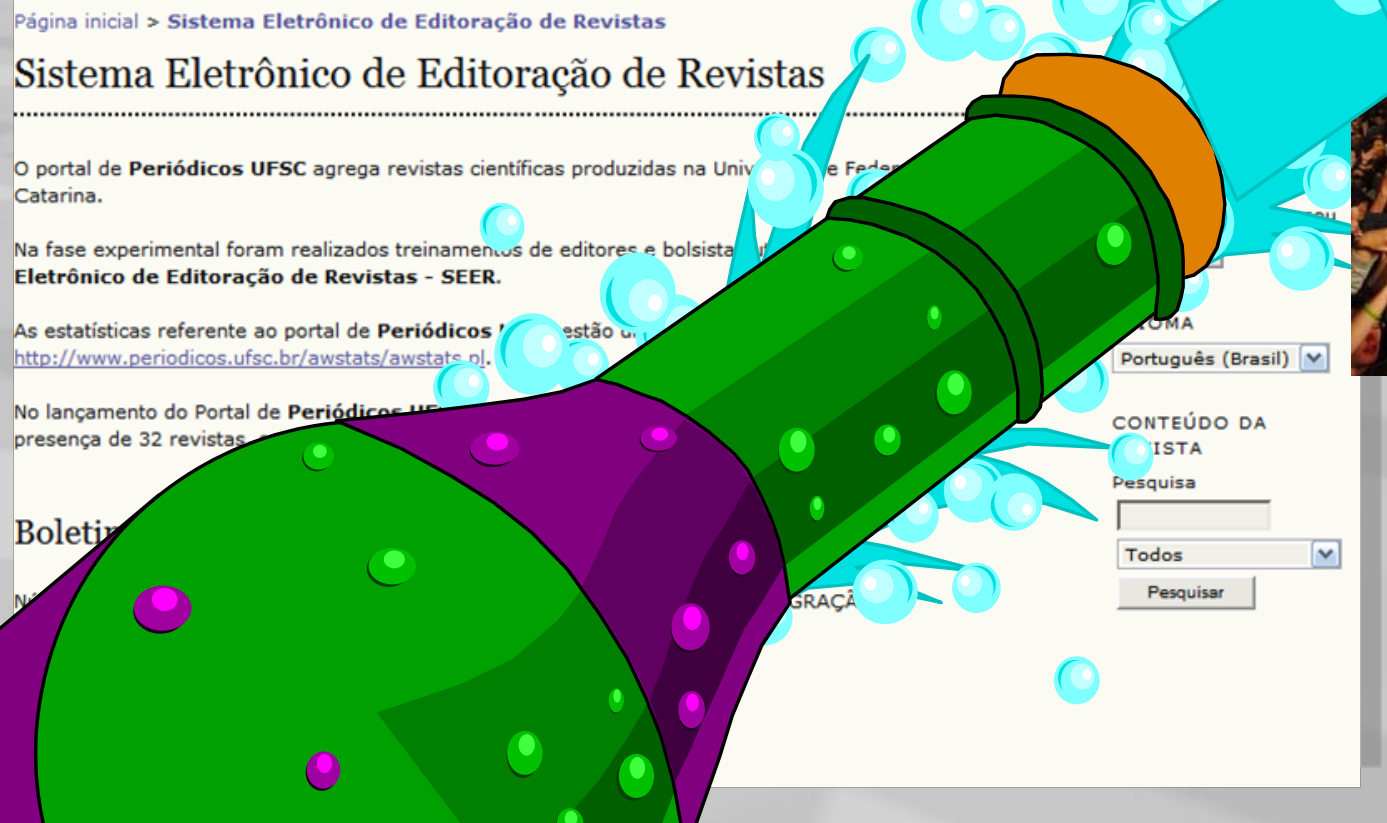

PKP

PUBLIC

KNOWLEDGE

PROJECT

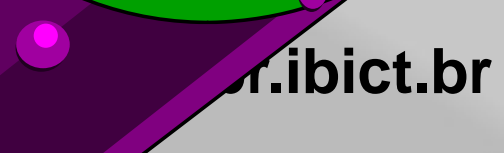

http://pkp.sfu.ca/?q=ojs 


\section{Quais serão alguns dos próximos desafios?}

Atendendo as novas demandas 


\section{Interoperabilidade}

O Portal da UFSC deve estar conectado às outras iniciativas nacionais em informação em C\&T. 


\section{Interoperabilidade: \\ Portal de Periódicos - CAPES}

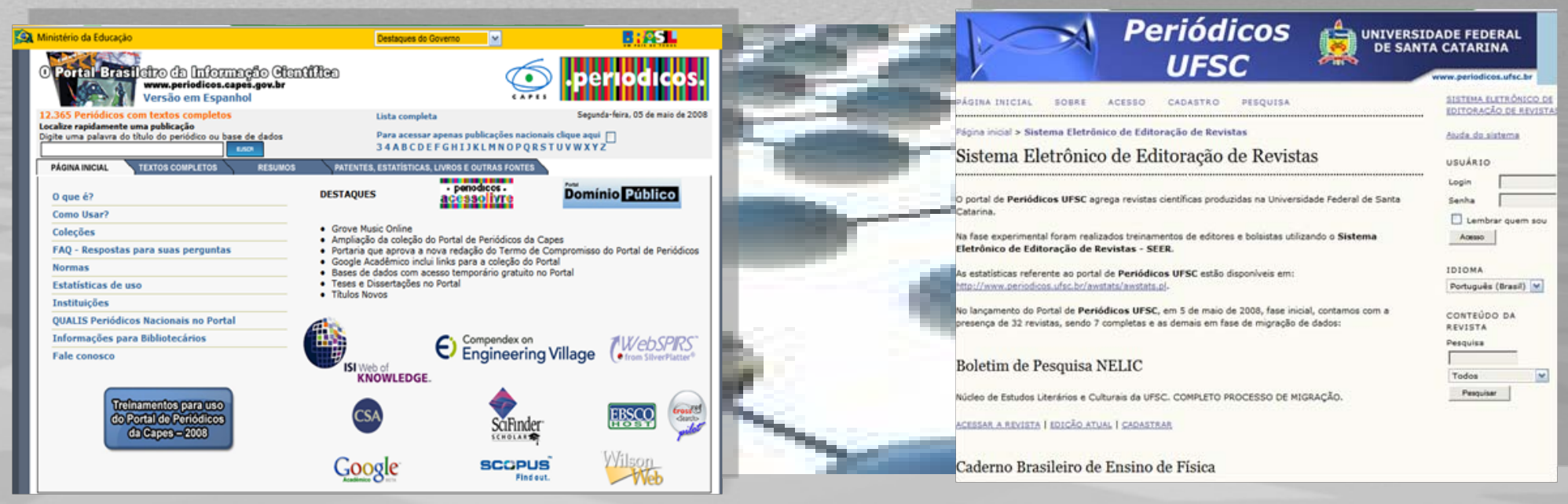

- Deve buscar equidade de qualificação dos periódicos que abrigar (critérios)

- Pode repetir êxito do "Google acadêmico" nas pesquisas realizadas em seu site. 


\section{Interoperabilidade:}

\section{Portal ScIELO - BIREME}

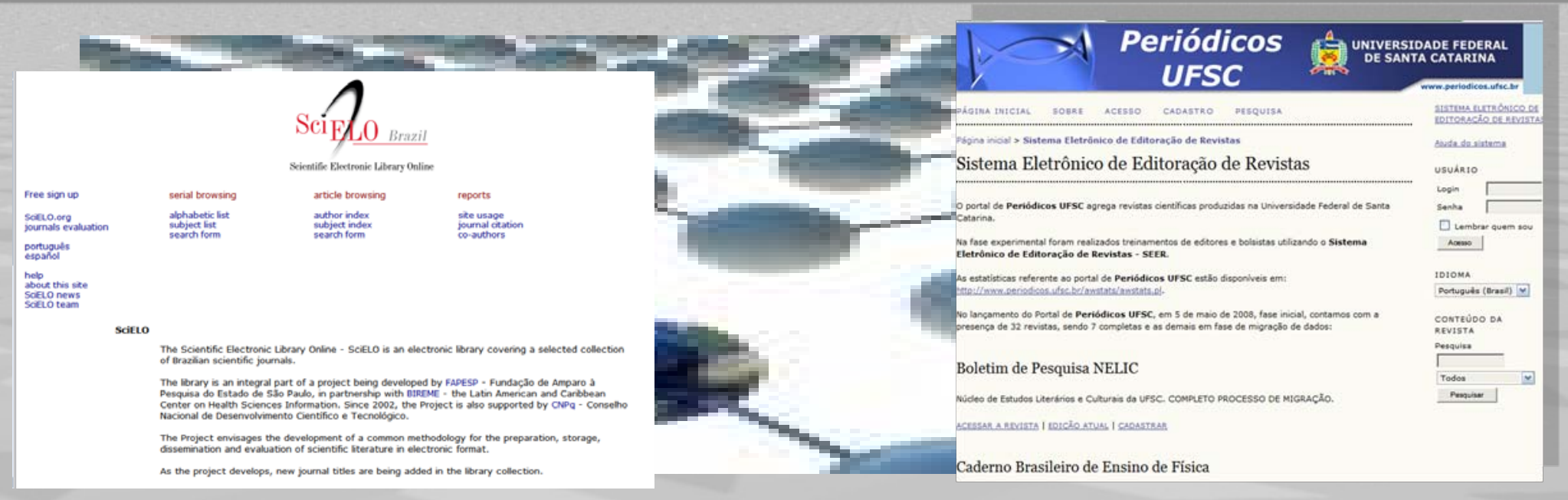

- Pode buscar interoperabilidade entre serviços de buscas

- Pode buscar espaço para seus periódicos no espaço público (e prestigiado) do SciELO

- Pode ser inspirar no modelo internacionalizado com respeito ao espaço regional para divulgação e construção de ciência 


\section{Interoperabilidade: \\ Plataforma Lattes - CNPq}

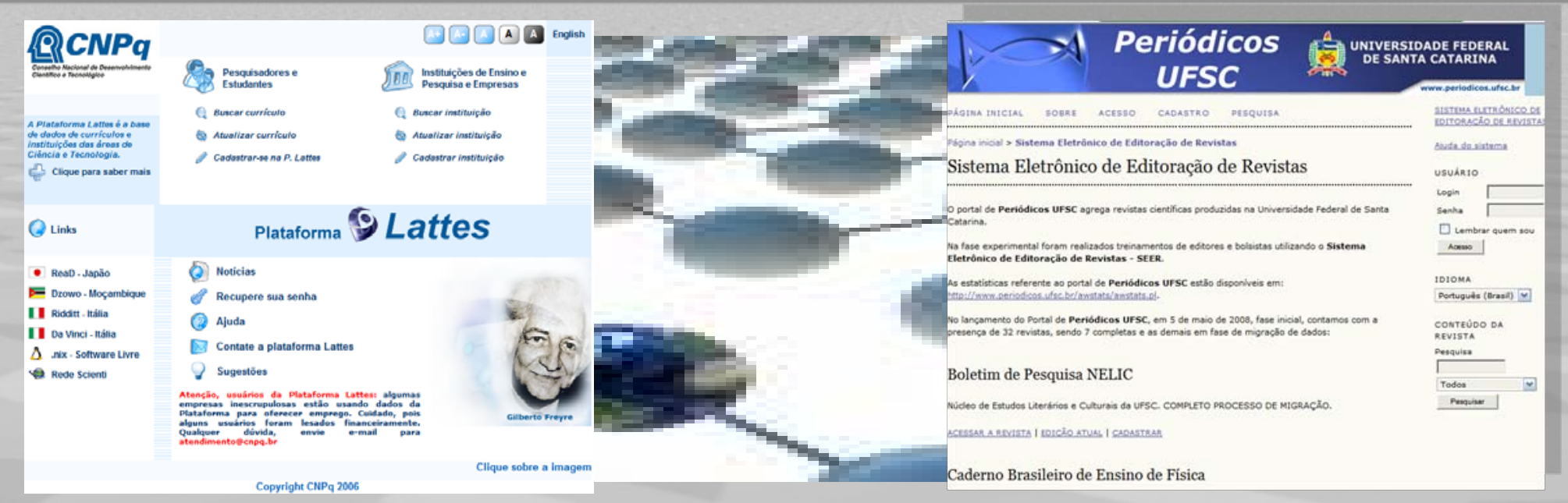

- Pode buscar interoperabilidade entre serviços de buscas:

- Link artigo - currículos dos autores

- Link autor - currículo

- Pode buscar modelo DOI de identificação de artigos

- Pode buscar modelo Web services do CVLattes de reconhecimento de journals mencionados no currículo 


\section{Interoperabilidade: \\ Plataforma Coleta - CAPES}

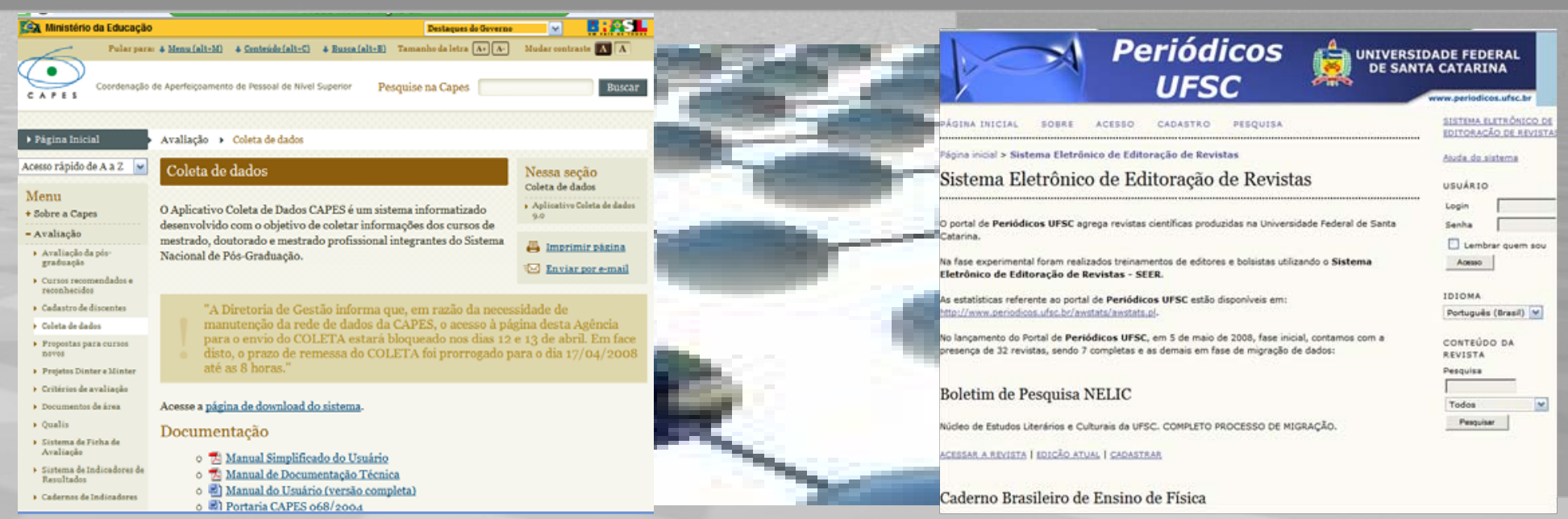

- Política que considere qualificação dos periódicos na Avaliação Qualis

- Interoperabilidade com serviços CAPES

- Link entre autores e dados da pós-graduação 


\section{Interoperabilidade: BDTD - IBICT}

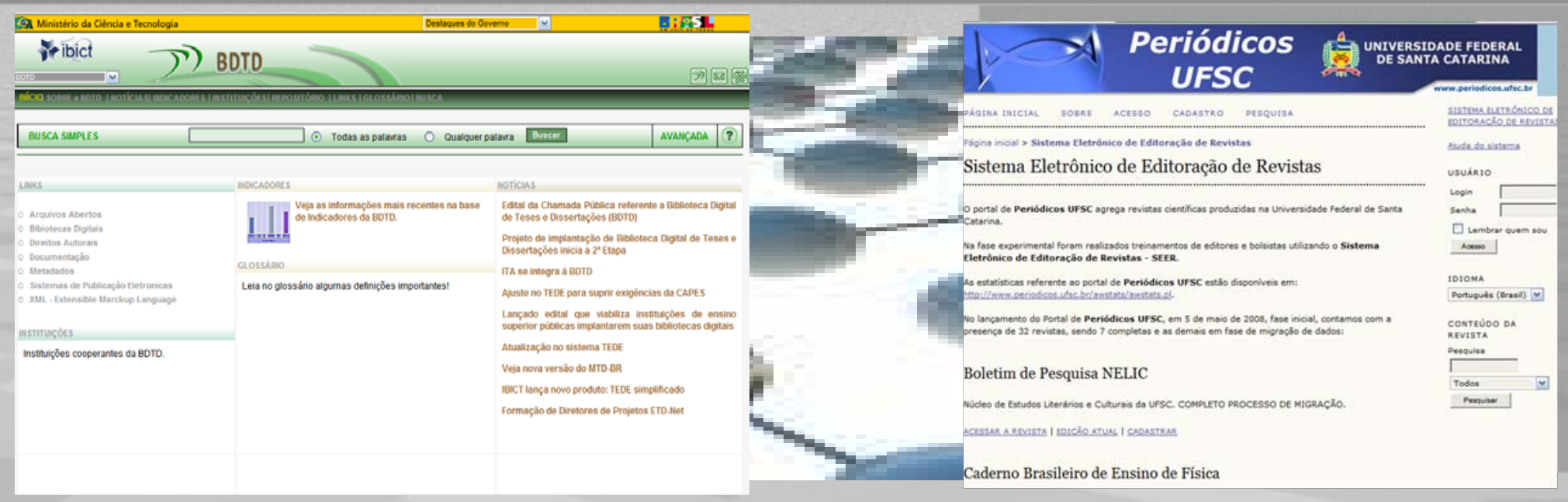

- Tradição da UFSC na publicação de Teses e Dissertações na Web (1a publicação institucional no mundo - PPGEP, 1995)

- Interoperabilidade com serviços BDTD

- Estudo dos padrões XML publicados pela BDTD

- Link autores - teses/dissertações relacionadas (orientadores e autores) 


\section{Interoperabilidade: \\ Portal SINAES - MEC}

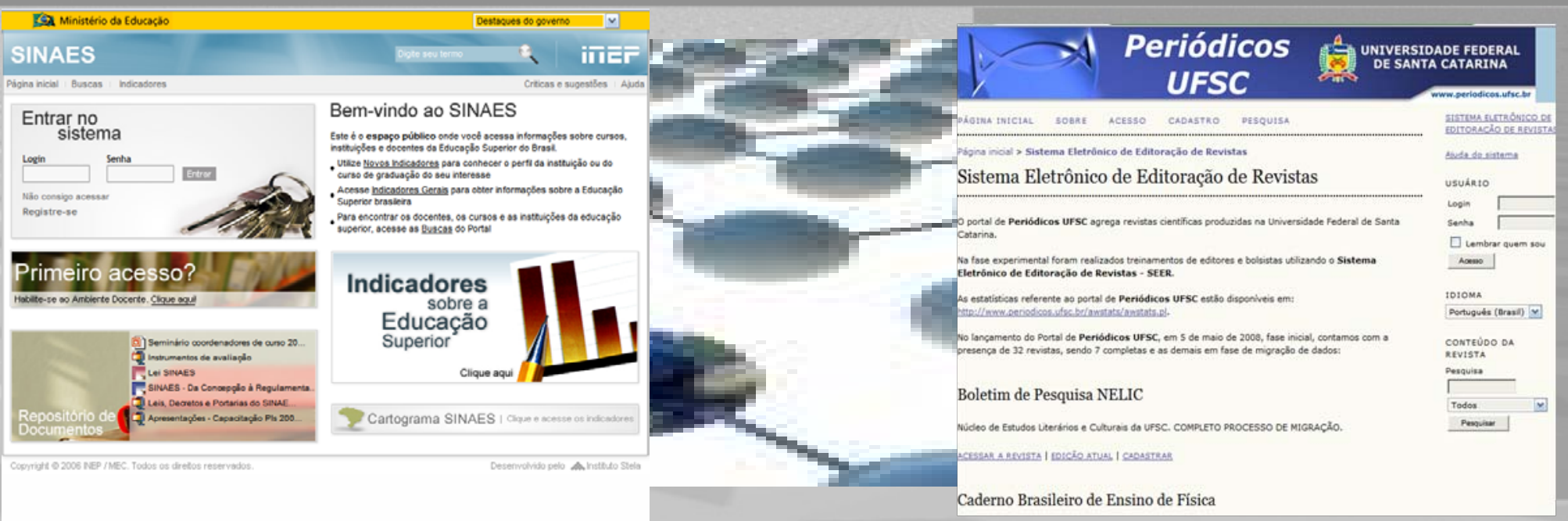

- Principal referência para a avaliação institucional e de cursos da UFSC

- Interoperabilidade com serviços do Portal SINAES

- Solicitação ao INEP para publicação de web services

- Serviços possíveis:

- Link artigos para página dos professores autores da UFSC

- Link artigos para página dos cursos dos autores 


\section{Interoperabilidade: \\ Portal Inovação - MCT}
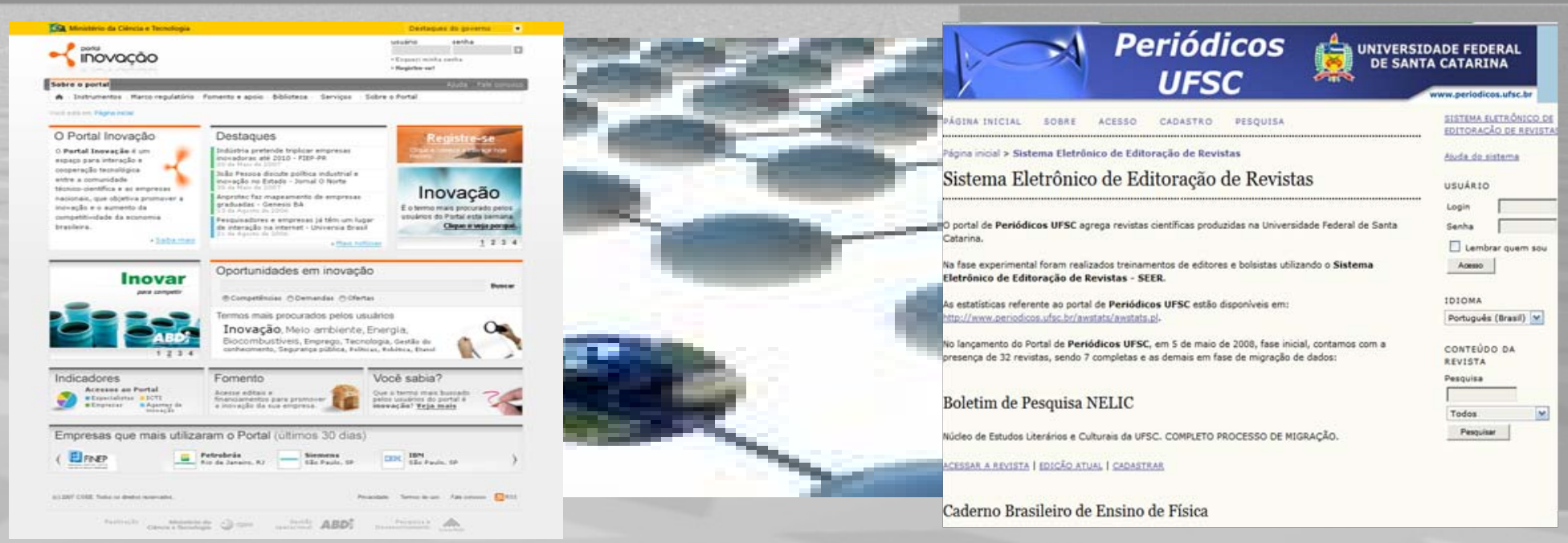

- Sintonia com a principal demanda da sociedade brasileira: aproximar a ciência da inovação empresarial

- Interoperabilidade com serviços do Portal Inovação

- Estudo dos padrões XML publicados pelo Portal

- Serviços possíveis:

- Link artigos para demandas/ofertas/competências nacionais

- Link artigos para mapas de conhecimento no país na área do artigo

- Comunidades de Prática do Portal Inovação 


\section{Interoperabilidade: Com toda a Web}

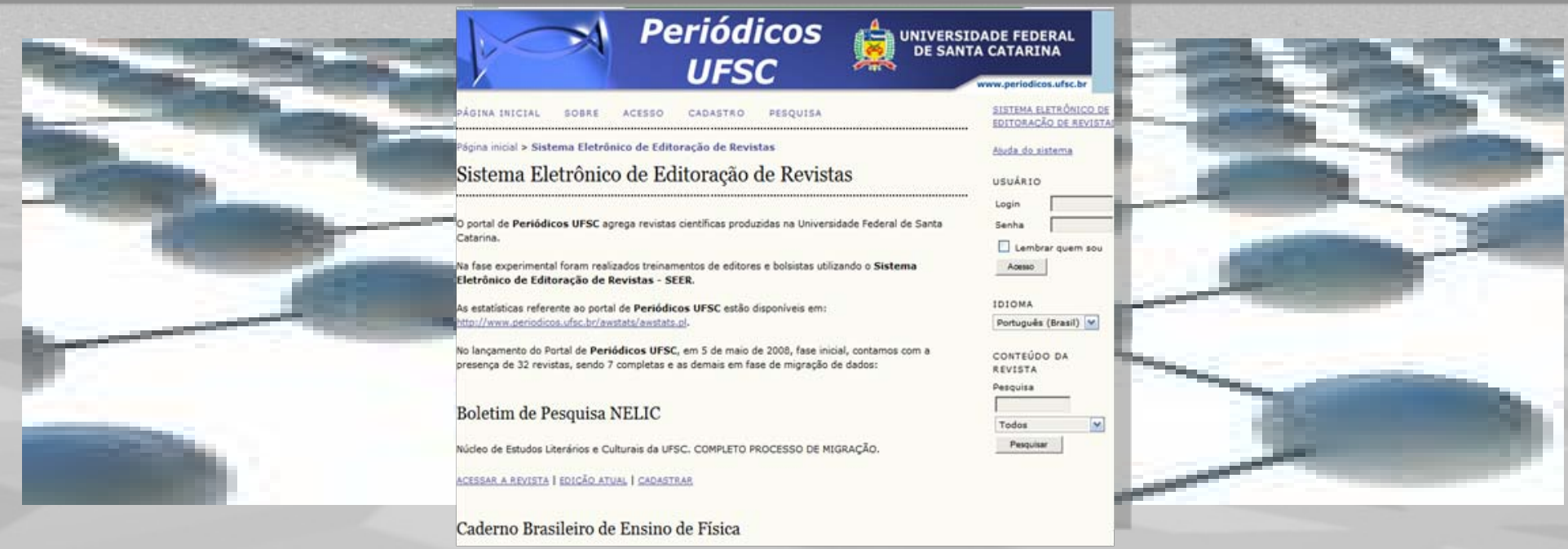

- Wikipedia

- Wikifier

- Google Acadêmico

$\bullet \quad \ldots$ 


\section{Redes Sociais}

O Portal da UFSC deve promover e prospectar redes na construção da ciência da universidade 


\section{Redes Sociais:}

\section{Prospectar e conectar redes}

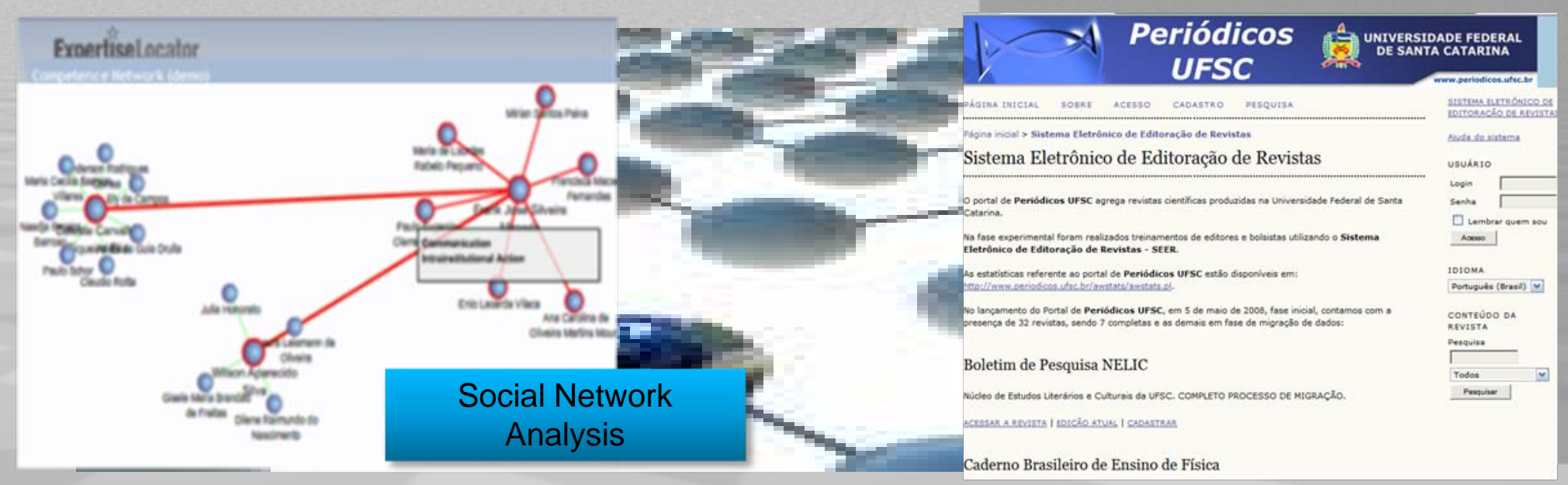

- Deve promover e conhecer a sociologia que dá bases para sua construção científica

- Quem são os autores? Quem trabalha com quem? Que conhecimentos multidisciplinares estão deixando de ser explorados na universidade? Quem deveria estar trabalhando com quem? 


\section{Redes Sociais:}

\section{Prospectar e conectar redes : EXEMPLO EGC}

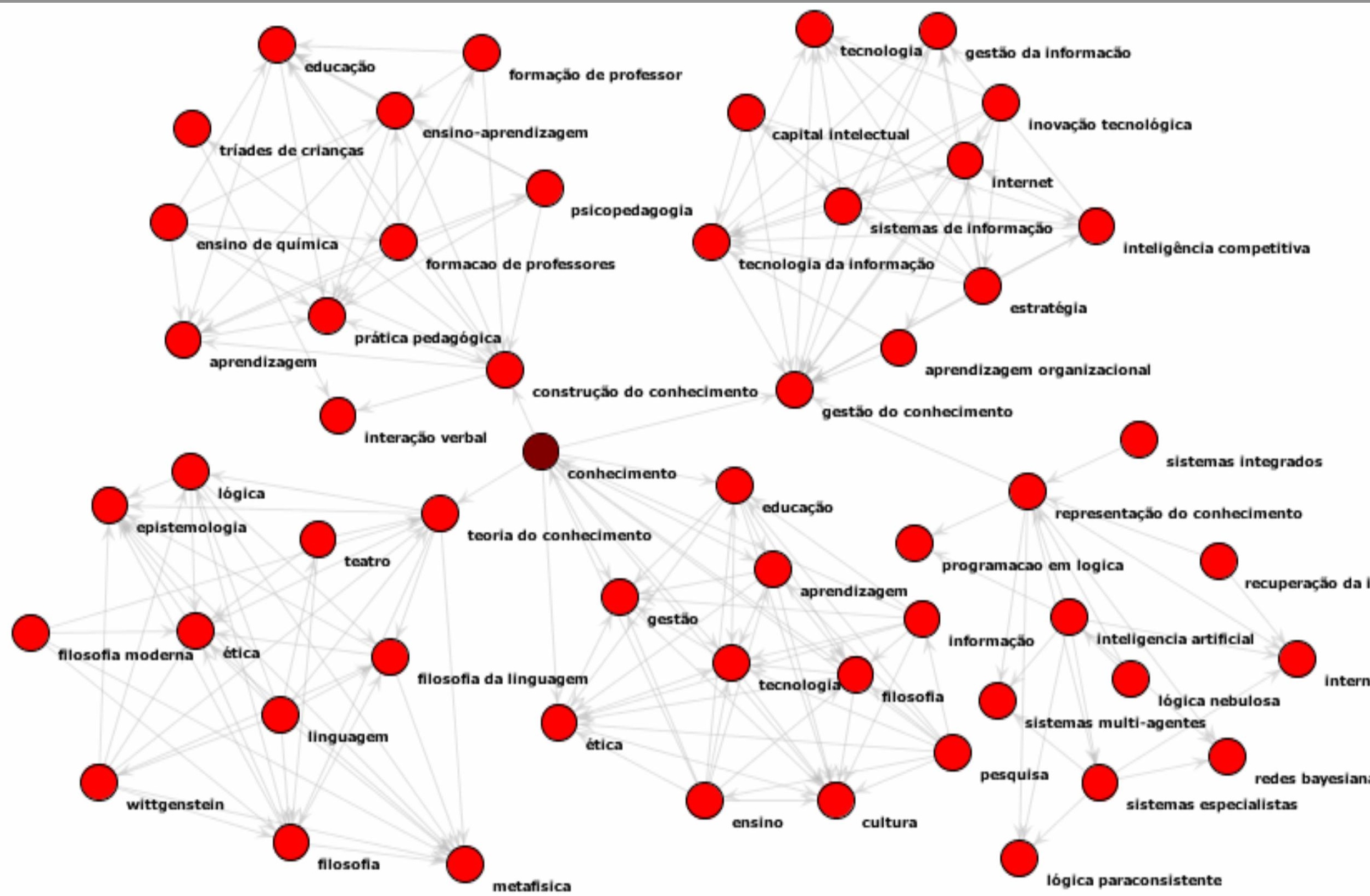




\section{Comunidades de Prática}

O Portal da UFSC deve se ampliar para abrigar as comunidades científicas da UFSC 


\section{CoPs:}

\section{Indo muito além dos papers...}

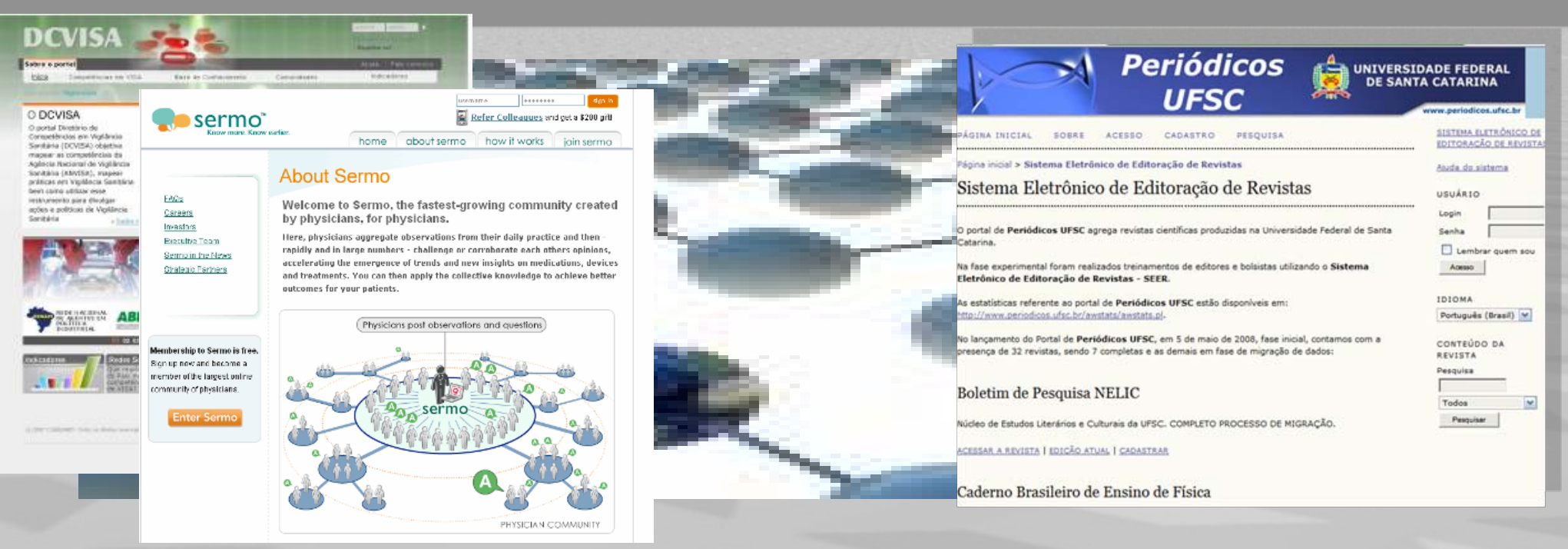

- Deve ser plural e promover múltiplas identidades

- Muito além da publicação

- Fóruns; Blog; Vídeos; Notícias; webcast

- Exemplo: SERMO (Saúde) 


\section{Financiamento}

O Portal da UFSC exige sintonia com os novos modelos de sustentabilidade da sociedade do conhecimento 


\section{Financiamento:}

\section{Como tornar o portal sustentável}

- Não pode haver redundância

- Nem Tecnológica

- Nem Humana

- Deve-se repensar o modelo de financiamento de periódicos

- Financiar um periódico via Portal (não independentemente)

- Financiar pesquisas e crescimento do Portal é financiar seus periódicos

- O Portal pode inovar utilizando o conceito de capital digital

- Por que a universidade pode alugar seu centro de convenções, mas não pode alugar seus sites? 


\section{Como colocar a UFSC em um novo patamar de produção de conhecimento?}

O desafio maior... 


\section{Quando estaremos nesta lista?}

\section{Performance Ranking of Scientific Papers for World Universities}

Copyright @ 2007 Higher Education Evaluation and Accreditation Council of Taiwan IE Ver.6.0 is suggested to browse the website

\begin{tabular}{|c|c|c|c|c|c|c|c|c|c|c|c|c|}
\hline $\begin{array}{l}\text { World } \\
\text { rank }\end{array}$ & University & $\begin{array}{l}\text { Country } \\
\text { rank }\end{array}$ & $\begin{array}{l}11 \text { years } \\
\text { articles }\end{array}$ & $\begin{array}{l}\text { Current } \\
\text { articles }\end{array}$ & $\begin{array}{l}11 \text { years } \\
\text { citations }\end{array}$ & $\begin{array}{l}\text { Current } \\
\text { citations }\end{array}$ & Ave citations & $\mathrm{H}$-index & HiCi papers & $\begin{array}{l}\text { Hi-Impact } \\
\text { journal } \\
\text { articles }\end{array}$ & $\begin{array}{l}\text { Fields of } \\
\text { excellence }\end{array}$ & $\begin{array}{l}\text { Total } \\
\text { score }\end{array}$ \\
\hline 94 & $\begin{array}{c}\text { University of São } \\
\text { Paulo }\end{array}$ & 1 & 34.62 & 38.14 & 7.35 & 11.41 & 13.38 & 34.88 & 4.35 & 12.51 & 81.82 & 27.34 \\
\hline 331 & $\begin{array}{c}\text { Federal } \\
\text { University of Rio } \\
\text { de Janeiro }\end{array}$ & 2 & 13.32 & 12.13 & 2.68 & 3.25 & 12.70 & 23.26 & 0.86 & 3.29 & 45.45 & 14.02 \\
\hline 332 & $\begin{array}{l}\text { State University } \\
\text { of Campinas }\end{array}$ & 3 & 14.72 & 18.58 & 2.91 & 4.16 & 12.47 & 19.77 & 1.56 & 4.68 & 40.91 & 13.95 \\
\hline 462 & $\begin{array}{c}\text { Federal } \\
\text { University of Rio } \\
\text { Grande do Sul }\end{array}$ & 4 & 8.08 & 8.58 & 1.80 & 2.36 & 14.07 & 18.60 & 0.89 & 2.39 & 27.27 & 10.26 \\
\hline 478 & $\begin{array}{c}\text { Federal } \\
\text { University of } \\
\text { Minas Gerais }\end{array}$ & 5 & 7.67 & 8.26 & 1.42 & 2.30 & 11.65 & 20.93 & 0.72 & 2.27 & 22.73 & 9.89 \\
\hline 485 & $\begin{array}{l}\text { São Paulo State } \\
\text { University }\end{array}$ & 6 & 9.89 & 10.55 & 1.43 & 2.08 & 9.14 & 15.12 & 0.50 & 1.70 & 31.82 & 9.73 \\
\hline
\end{tabular}


Conclusões 


\section{Concluindo...}

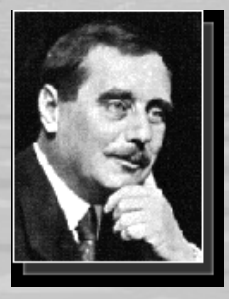

Herbert George Wells

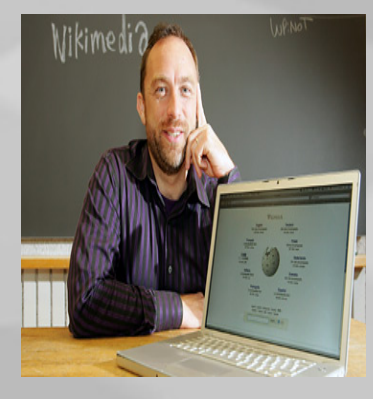

Jimmy Wales
- A UFSC pode ter dado o passo hoje para construir a sua "enciclopédia permanente"

- A UFSC como organização de conhecimento

- Os desafios são grandiosos (assim como as recompensas)

- Gestores de conteúdo podem catalisar ou dificultar o alcance destas conquistas

- A única certeza é que o êxito é gerador geométrico de demanda:

- +conteúdo -> +colaboração -> +compartilhamento $->$ +comunicação $->$ +recursos 
Mesa Redonda: A comunicação científica no Brasil: estratégias de diálogo científico em âmbito internacional

\section{Na estrada de Wells a Wales: \\ O que esperar nos próximos passos do Portal da UFSC}

\section{MUITO OBRIGADO!}

\section{Roberto Pacheco}

Programa de Pós-Graduação em Engenharia

e Gestão do Conhecimento - UFSC

pacheco@egc.ufsc.br 


\section{Agenda}

\section{- Introdução}

- Perspectiva histórica

- Mudança de paradigmas

- Conquistas do Portal da UFSC

- Alinhamento com tendências mundiais

- Perspectivas para a produção científica da UFSC

- Impacto na produção científica do Estado

- Próximos desafios

- Atender às novas demandas

- Conectividade global: interoperabilidade

- No País: PORTAL DA CAPES; SCIELO; PLATAFORMA LATTES; COLETA/CAPES; BDTD/IBICT; PORTAL INOVAÇÃO

- No Mundo: Wikipedia, Conceptual Web

- Compreendendo a sociologia da ciência: redes sociais

- Ampliando os espaços comunitários: comunidades de prática

- Gerando mais ciência: engenharia do conhecimento

- Financiar com um novo modelo

- Financiamento público editorial

- Digital capital

- Colocar a UFSC em um novo patamar na produção de conhecimento 